Revue bibliographique pour le domaine irano-aryen

Volume 37-38-39 | 2018

Comptes rendus des publications de 2014-2016

\title{
Agnès Devictor. Images, combattants et martyrs. La guerre Iran-Irak vue par le cinéma iranien
}

\section{Marcel Bazin}

\section{(2) OpenEdition}

1 Journals

\section{Édition électronique}

URL : http://journals.openedition.org/abstractairanica/46141

DOI : 10.4000/abstractairanica.46141

ISBN : 1961-960X

ISSN : 1961-960X

Éditeur :

CNRS (UMR 7528 Mondes iraniens et indiens), Éditions de l'IFRI

Référence électronique

Marcel Bazin, « Agnès Devictor. Images, combattants et martyrs. La guerre Iran-Irak vue par le cinéma iranien », Abstracta Iranica [En ligne], Volume 37-38-39 | 2018, document 1, mis en ligne le 30 décembre 2018, consulté le 26 septembre 2020. URL : http://journals.openedition.org/abstractairanica/46141 ; DOI : https://doi.org/10.4000/abstractairanica.46141

Ce document a été généré automatiquement le 26 septembre 2020

Tous droits réservés 


\section{Agnès Devictor. Images, combattants et martyrs. La guerre Iran-Irak vue par le cinéma iranien}

Marcel Bazin 


\section{RÉFÉRENCE}

Agnès Devictor. Images, combattants et martyrs. La guerre Iran-Irak vue par le cinéma iranien. Téhéran - Paris, IFRI - IISM - Karthala, 2015, 487 p., illustrations, bibliographie et filmographie, index. (coll. Terres et gens d'islam), ISBN IFRI : 978-2-909961-57-6 et ISBN KARTHALA : 978-2-8111-1420-6

1 Après avoir donné un ouvrage essentiel sur la politique du cinéma dans la République islamique d'Iran (Cf. compte rendu dans AbstIr 27-2006), Agnès Devictor apporte ici un nouveau livre majeur, élaboré parallèlement à une habilitation à diriger des recherches soutenues à l'EHESS en mars 2015, Formes de croyances, formes combattantes, formes cinématographiques. Souhaitant revenir sur ce cinéma de guerre iranien qui n'avait occupé qu'un chapitre dans sa thèse, elle est repartie en Iran effectuer un travail considérable d'inventaire et d'entretiens. La mise en œuvre des matériaux ainsi rassemblés croise une vaste culture cinématographique et l'analyse des spécificités culturelles de la société iranienne et de l'islam shi'ite, le tout jalonné par l'étude d'œuvres cinématographiques précises illustrées par de nombreuses captures d'écran. Une première partie présente la guerre Iran-Irak puis analyse la manière dont elle a été filmée. La deuxième partie décrypte les liens entre l'imaginaire shi'ite et la mise en scène cinématographique de la guerre, avec entre autres la transposition de la mythologie de Karbalâ et l'exaltation du martyre. Une troisième partie concentre la focale sur le corpus de films documentaires réalisés par Mortezâ Avini qui mobilise la modernité technique au service de l'ancrage dans la tradition mystique.

Un compte-rendu critique détaillé est paru dans Studia Iranica 45 (2016).

\section{AUTEURS}

\section{MARCEL BAZIN}

Université de Reims Champagne-Ardenne 